\title{
ARtigos
}

\section{Momento histórico de uma especialidade}

\section{Historical moment of a specialty}

\author{
Daniel Romero Muñoz ${ }^{(1)}$, Daniele Muñoz-Gianvecchio(2), \\ Victor A. P. Gianvecchio(3)
}

Muñoz DR, Muñoz-Gianvecchio D, Gianvecchio VAP. Momento histórico de uma especialidade. Saúde, Ética \& Justiça. 2010;15(2):69-74.

RESUMO: Os autores fazem um breve relato histórico da Medicina Legal ressaltando que é, como especialidade médica, uma das mais antigas e que vive um momento de grande relevância histórica: a fusão de duas sociedades médicas que disputavam o direito de emitir certificado de área de atuação para os médicos que a exercem. Os pontos principais dessa disputa são destacados, incluindo a alteração do nome da especialidade que passou a ser Medicina Legal e Perícia Médica, não se tratando de nova especialidade, apenas uma pequena mudança de denominação da antiga.

DESCRITORES: Medicina legal/história; Sociedades médicas/história; Especialidade/história; Brasil.

(1) Professor Titular de Medicina Legal, Universidade de São Paulo, Faculdade de Medicina, Departamento de Medicina Legal, Ética Médica, Medicina Social e do Trabalho, São Paulo, SP, Brasil.

(2) Médica, Especialista em Medicina Legal pela Universidade de São Paulo, Faculdade de Medicina, Departamento de Medicina Legal, Ética Médica, Medicina Social e do Trabalho, São Paulo, SP, Brasil.

(3) Médico, Especialista em Medicina Legal pela Universidade de São Paulo, Faculdade de Medicina, Departamento de Medicina Legal, Ética Médica, Medicina Social e do Trabalho, São Paulo, SP, Brasil.

Endereço para correspondência: Daniel Romero Muñoz. Instituto Oscar Freire - FMUSP, Av. Dr. Arnaldo, 455 - São Paulo, SP, Brasil. CEP: 01246-903. E-mail: danielmunoz@ bol.com.br 


\section{INTRODUÇÃO}

E stamos vivendo um momento de grande relevância histórica para a Medicina Legal e as Perícias Médicas brasileiras. Após uma luta renhida entrea Associação Brasileira de Medicina Legal (ABML) e a Sociedade Brasileira de Perícias Médicas (SBPM) a respeito de questões ideológicas e, mais especificamente, sobre o direito de certificar área de atuação em perícias médicas, que chegou até a esfera judicial, o Conselho Federal de Medicina (CFM) convocou ambas as entidades e, após duas reuniões conjuntas, comunicou sua conclusão e conclamouas para o estabelecimento de uma solução pacífica: - A especialidade é uma só, mas temos duas sociedades médicas disputando o direito de regêla; o ideal é a fusão de ambas para constituírem uma Sociedade de Especialidade que represente todos os profissionais da área. Sugeriu que o nome da nova Sociedade, para evitar disputas, contivesse a designação das duas entidades anteriores, ou seja, fosse denominada Associação Brasileira de Medicina Legal e Perícias Médicas. Por extensão, a especialidade médica, apesar de não ser uma nova especialidade médica, passaria a chamar-se Medicina Legal e Perícias Médicas, para apaziguar as principais divergências ideológicas das duas entidades. As diretorias da SBPM e ABML levaram a proposta para as respectivas Assembléias Gerais - que ocorreram em setembro de 2010 (Congresso Brasileiro de Perícias Médicas - Aracajú) e em outubro do mesmo ano (Congresso Brasileiro de Medicina Legal - Cuiabá) - que a aprovaram. Cada sociedade constituiu uma comissão com quatro membros para, em reuniões conjuntas, elaborarem o estatuto e realizarem as demais formalidades para a fusão de ambas. O CFM, cientificado da decisão das Assembléias Gerais, acionou a Comissão Mista de Especialidade (CME) - composta de membros da Associação Médica Brasileira (AMB), da Comissão Nacional de Residência Médica (CNRM) e do próprio CFM - visando a emissão de uma resolução do CFM para legalizar o assunto.

\section{ANTECEDENTES: A LUTA}

O que motivou a intervenção do CFM?

A disputa entre a ABML e a SBPM começou, em termos regulamentares, com a Resolução CFM 1845, publicada em julho de 2008, embora suas divergências ideológicas e políticas já viessem manifestando-se há alguns anos. A resolução dava à SBPM o direito de certificar área de atuação em perícias médicas. Ato contínuo, a Associação
Médica Brasileira (AMB) firmou convênio com a SBPM para que esta assumisse o seu Departamento de Perícias Médicas e pudesse, assim, certificar a área de atuação em perícias médicas.

Ocorre que a Medicina Legal, especialidade médica representada pela $A B M L$, tem residência médica, aprovada e avalizada pela CNRM e pela CME, cujo objetivo é formar especialistas em perícias médicas. Ademais, pelas regulamentações anteriores - que também constavam dessa resolução 1845/2008 - somente Sociedades de Especialidade podiam certificar área de atuação e a SBPM não o era. Após alguns embates, a ABML moveu ação judicial contra o CFM, a AMB e a CNRM mostrando essas incongruências. Reconhecendo tais falhas, o CFM emitiu nova resolução em setembro de 2009 (Resolução CFM 1930/2009) revogando os itens referentes a perícia médica contidos na Resolução $1845 / 2008$.

Nesse ínterim, entretanto, a SBPM, valendose do direito que lhe dava a Resolução 1845/2008, já havia feito um concurso público para certificar a área de atuação em perícias médicas e aprovado 118 médicos. Como o concurso foi feito durante a vigência dessa resolução, esses médicos adquiriram o direito ao certificado, motivando, então, uma ação judicial movida pela SBPM contra o CFM pela revogação da Resolução 1845/2008. Face às ações judiciais impetradas e o impasse criado, o CFM convocou ambas as entidades para se encontrar a solução e encerrar as disputas.

\section{DIVERGÊNCIAS IDEOLÓGICAS}

As principais divergências ideológicas entre a $A B M L$ e a SBPM podem ser assim resumidas:

1a) A ABML conceitua a perícia médica como um procedimento próprio da Medicina Legal e, portanto, a titulação na área cabe a essa especialidade;

$2^{a}$ ) A SBPM defende que a Medicina Legal restringe-se à perícia criminal, sendo, no Brasil, exercida apenas nos Institutos Médico Legais - IML e, como a SBPM representa em nosso País todas as perícias médicas, logo, a Medicina Legal (perícia criminal) é uma das suas áreas de atuação.

Tomando como base a conclusão do CFM de que são duas sociedades médicas disputando a mesma especialidade, vemos que no âmago dessa discussão ideológica há uma questão que deve ser claramente formulada e que exige uma acurada reflexão, tendo em vista os fatos supracitados: - Por que uma especialidade médica, tradicional como a Medicina Legal, abrigou em seu seio tão acirrada disputa ideológica entre médicos que realizam o 
Muñoz DR, Muñoz-Gianvecchio D, Gianvecchio VAP. Momento histórico de uma especialidade.

mesmo tipo de atividade, as perícias médicas?

O cerne do problema vai além da certificação da área de atuação e para entendê-lo faz-se necessária uma análise mais profunda da evolução da especialidade.

\section{ESBOÇO HISTÓRICO DA ESPECIALIDADE}

A Medicina Legal é uma das mais antigas especialidades médicas. Ela nasceu, oficial e legalmente, em 1507 na Alemanha, com a promulgação do Código de Bamberg, que determinava a atuação de médicos em processos judiciais. Em 1532 a Constituição de Carlos V instituiu a mesma obrigação na França1. Esse exemplo foi seguido por outros países, passando a ser norma em quase todo o mundo.

Como conseqüências da instituição da atividade médico-forense houve o desenvolvimento de uma literatura médico-legal e a criação de um corpo de doutrina próprio da Medicina Legal. As primeiras obras sobre o tema foram de Ambroise Paré (França, 1575) e de Fedele (Itália, 1602), porém, foi o tratado Questões médico-legais, escrito pelo perito médico do Vaticano Paolo Zacchia (Itália), em1621, que levou à adoção do nome Medicina Legal e é considerado como o primeiro tratado da especialidade ${ }^{2}$.

Em virtude da importância social e legal que foi adquirindo a atividade médico-forense e do desenvolvimento de técnicas e de doutrina próprias, houve a necessidade de formação de médicos para atuarem nessa área, surgindo, então, o apelo para o ensino da especialidade. As primeiras cátedras de Medicina Legal foram criadas nas Universidades alemãs, no século XVIII, onde a disciplina era ministrada junto com outras matérias de cunho social, como a Saúde Pública. Em seguida vieram:

- A primeira cátedra oficial de Medicina Legal, em Nápoles (1789) e o primeiro curso de Medicina Legal na França, mais especificamente na Universidade de Paris (1794) ${ }^{3}$;

- A primeira cátedra independente de Medicina Legal, Universidade de Viena (1804).

A partir dessas universidades espalhouse para o mundo todo: - Edimburgo, Escócia (1807), Universidade de Colúmbia, EUA (1813), Universidade de Harvard (1815), Universidade de Buenos Aires (1823) ${ }^{1}$.

No Brasil, a primeira cátedra de Medicina Legal foi inaugurada em 1832 no Rio de Janeiro 4 .

\section{ÁREAS DE ATUAÇÃO DA MEDICINA LEGAL}

Mas qual era a disciplina lecionada, ou melhor, o ensino acadêmico da Medicina Legal visava a formar profissionais para atuarem em que áreas? Quais eram as áreas de atuação da Medicina Legal?

$\mathrm{Na}$ França, o Manual Completo de Medicina Legal, de Briand e Chaudé, editado em 1874, assinalava que a ML tratava, do ponto de vista técnico, de Questões de Direito civil, criminal e administrativo, como ciência auxiliar do Direito ${ }^{5}$.

E as perícias trabalhistas, não faziam parte da Medicina Legal?

A perícia médica é decorrência da necessidade de provas para enquadrar determinado caso na legislação específica. Legislação trabalhista é posterior a essa publicação; no Brasil, surgiu na década de 1930. Obviamente não poderia haver perícia trabalhista antes do aparecimento da legislação que regulava essas questões. Entretanto, Flamínio Fávero, emseulivro Medicina Legal, editado em 1938, já incluía o capítulo da Infortunística, no qual tratava da perícia nos acidentes do trabalho e moléstias profissionais e, em edições posteriores afirmava: - "Na 3". edição inclui as modificações da lei de acidentes do trabalho". Esse mesmo autor define o campo de atuação da Medicina Legal da seguinte forma: - "É inegável que esta disciplina (...) não mais atua, apenas, no esclarecimento de certas questões de processo civil e criminal, nem tampouco, somente em aplicações forenses. Hoje a medicina legal age e deve agir pela "aplicação dos conhecimentos médico-biológicos na elaboração e execução das leis que deles carecem"4.

E a Seguridade Social, isto é, as Perícias Previdenciárias?

O Prof. Franchini (Itália) divide a Medicina Legal em "Medicina Legale in Materia Penale" e "Medicina Legale in Materia Civile" e afirma: - "...a Medicina Legal italiana compreende a Medicina da previdência social e do seguro social e privado e desse modo se ocupa, no plano pericial, de todas as questões atinentes aos acidentes de trabalho, às moléstias profissionais, à invalidez e a todas as questões médico legais da seguridade social"6.

O periódico ZACCHIA, uma das mais antigas revistas de Medicina Legal, destaca entre as questões médico-legais as relativas às perícias previdenciárias ${ }^{7}$.

Na França, a "Medicinae Légale Sociale" trata das perícias da previdência social, dividindoas (pelo tipo de benefício) em seguro: - Doença, Maternidade, Invalidez, Velhice, Acidente de trabalho e Outros ${ }^{8}$.

$\mathrm{Na}$ Argentina, as perícias trabalhistas e previdenciárias são englobadas como Medicina Legal do Trabalho e da Seguridade Social ${ }^{9}$. 
No Brasil, o Prof. Hermes de Alcântara, da Universidade de Brasília, afirma em seu livro Perícia Médica Judicial: - Os objetivos da Medicina Legal são (...) realizar, com arte e base científica, qualquer exame pericial"10.

Em outras palavras, o campo de atuação da Medicina Legal abrange todas as perícias médicas, sejam elas judiciais ou extra judiciais (administrativas lato senso), estando bem estabelecido do ponto de vista acadêmico.

Além disso, a própria evolução do Direito, com o surgimento de novas legislações, cria a necessidade de novos tipos de perícia, fazendo evoluir a Medicina Legal.

\section{ASSOCIAÇÕES DE MEDICINA LEGAL E PERÍCIAS MÉDICAS NO BRASIL}

Em 18/04/62, 26 professores de Medicina Legal (Clóvis Meira, Estácio de Lima, Flamínio Fávero, Hélio Gomes, Milton Dantas, Nilton Salles, Teodorico de Freitas, Silva Telles ...), representando os diversos rincões deste País, reuniram-se em uma Jornada em São Paulo e fundaram a Ordem dos Peritos Médicos do Brasil, com a finalidade de congregar os profissionais da área. Na ocasião discutiram o ensino da especialidade e elaboraram dois programas de Medicina Legal: um para ser lecionado nas faculdades de medicina e outro para as faculdades de direito. Na formação médica deveria se tratar de questões cíveis e criminais de deontologia, identidade, traumatologia, tanatologia e sexologia, além da Medicina Social, que incluía a infortunística (perícias trabalhistas e de acidentes do trabalho), a seguridade social (perícias previdenciárias e administrativas), a Criminologia e a Psicopatologia. A formação do advogado deveria contemplar a Medicina Legal constituída, ou seja, a Medicina Legal Civil, a Penal, a Trabalhista, a Administrativa e a Jurisprudência médico legal, bem como a Medicina Legal constituenda (em elaboração), incluindo questões como a eutanásia, a pena de morte, a inseminação artificial, a esterilização de anormais etc.

Em 1967, em uma jornada de Medicina Legal ocorrida no Hotel Quitandinha, no Rio de Janeiro, professores da especialidade e outros profissionais da área fundaram a Sociedade Brasileira de Medicina Legal, que veio substituir a Ordem dos Peritos Médicos do Brasil. Essa entidade filiou-se à AMB, passando, com o aval desta, a emitir o título de especialista em Medicina Legal e mais tarde passou a designar-se Associação Brasileira de Medicina Legal - ABML.

Em 1989 foi fundada a Sociedade Brasileira de Perícias Médicas - SBPM. Seu embrião foi a associação médica criada no Departamento de Perícias Médicas do Estado de São Paulo, que realiza as perícias administrativas dos funcionários públicos estaduais. Congregaram-se a ela, posteriormente, os médicos peritos da Previdência Social (INSS) e também médicos que executavam outros tipos de perícias, tornando-a cada vez mais forte e representativa.

A $A B M$ e a SBM seguiram caminhos paralelos. $O$ ideal era a união de ambas uma vez que tratavam da mesma especialidade. Não tendo havido a união o confronto era inevitável e foi o que ocorreu.

\section{O GRANDE PROBLEMA DA ESPECIALIDADE}

O maior problema da especialidade hoje é a desunião entre os médicos peritos brasileiros, que foi causada fundamentalmente pela divergência ideológica e pela criação de associações distintas para congregarem profissionais da mesma classe (médica), que exerciam o mesmo tipo de atividade (perícias).

Essa desunião, em nossa opinião, deveu-se, principalmente, aos seguintes fatores:

\section{$\left.1^{\circ}\right)$ Um erro tático}

Um erro tático importante, cometido pelas sociedades regionais de Medicina Legal e também pela nacional, foi centrar os temas de seus eventos basicamente na área penal, fortalecendo assim a visão de que a especialidade estava ligada às perícias criminais.

$2^{\circ}$ ) Falta de uma busca perseverante de entrosamento

Outro fator de desunião foi as sociedades não terem buscado, de modo persistente, um entrosamento entre os peritos das diversas áreas da Medicina Legal, visando à melhoria e ao crescimento da própria especialidade.

\section{$3^{\circ}$ ) Uma visão distorcida da especialidade}

Os dois fatores acima citados são, porém, conseqüências de como os peritos médicos vêem a Medicina Legal e este é o principal problema para sua união. Esta visão que cada um tem da especialidade advém da distorção sofrida pela especialidade na prática e na educação médicas, da difusão deturpada do papel da Medicina Legal feita pela mídia, da deficiência dos mecanismos de formação acadêmica, além de outros fatores.

Como foi dito acima, o campo de atuação da Medicina Legal abrange todas as perícias médicas, 
Muñoz DR, Muñoz-Gianvecchio D, Gianvecchio VAP. Momento histórico de uma especialidade.

fato que está bem estabelecido do ponto de vista acadêmico. Na prática, entretanto, o ensino da Medicina Legal nas faculdades de medicina brasileiras tem que enfrentar, basicamente, dois tipos de obstáculos: o primeiro é a reduzida carga horária que lhe é atribuída, não permitindo lecionar todo o conteúdo proposto; o segundo é legal, isto é, o artigo 277 do Código de Processo Penal determina que a aceitação da perícia é obrigatória; assim sendo, se um médico é nomeado para realizar uma perícia no foro criminal, como norma, não pode se escusar da incumbência e terá que realizála. Esse artigo torna a Medicina Legal Criminal uma competência que todo médico tem que ter e, portanto, faz com que o programa de Medicina Legal dos cursos de graduação em Medicina seja centrado na parte criminal. Disto decorre que, na "cabeça dos médicos", a Medicina Legal se restrinja apenas às perícias criminais, exercida nos IML. Por outro lado, a parte mais sensacional da Medicina Legal é, sem dúvida, o necrotério, por isso a mídia transmite a idéia que o médico legista é o médico que "mexe com cadáveres", incutindo nas pessoas uma visão eminentemente tanatológica da especialidade.

A superação dessa divergência ideológica interna é fundamental para a união de todos os que se dedicam à especialidade e, principalmente, para mostrar à classe médica o que é a Medicina Legal, evitando assim que ocorra novamente o tipo de problema que ela teve que enfrentar em 1997:

- Nesse ano ocorreu a primeira reunião do CFM e AMB com a Comissão Nacional de Residência Médica (CNRM) na tentativa de unificar as listas de especialidades médicas reconhecidas pelas três entidades. $O$ motivo da reunião é que a CNRM reconhecia 48 especialidades médicas e o CFM e AMB tinha em sua lista 63 especialidades. Ao final desse encontro algumas especialidades médicas deixaram de sê-lo, entre elas a Medicina Legal. Motivo: - "A Medicina Legal só faz autópsia, que é um procedimento anátomo-patológico; portanto, ela é área de atuação da Patologia". Foram necessários três anos para reverter essa situação e voltar a ser reconhecida como uma especialidade médica.

\section{CONCLUSÃO: O GRANDE DESAFIO}

Vários problemas terão que ser enfrentados pela especialidade, merecendo destaque, em nossa opinião, a presença de advogados no exame médico pericial e a invasão dessa área médica por outros profissionais, como por exemplo, os fisioterapeutas.

Hoje, entretanto, a Medicina Legal e Perícias Médicas do Brasil está erigindo um dos maiores marcos de sua história e é nossa convicção que o seu maior desafio será superar a divergência ideológica que motivou a luta dentro da especialidade e congregar os médicos peritos brasileiros, que, segundo algumas estimativas, são em torno de 20.000 profissionais. A união dos mesmos fará com que ela esteja, certamente, entre as maiores especialidades médicas brasileiras e propiciará à Justiça, seu objetivo maior, profissionais gabaritados, técnica e eticamente, para fornecer os subsídios médicos necessários para que sejam resguardados os direitos das pessoas neste País.

Muñoz DR, Muñoz-Gianvecchio D, Gianvecchio VAP. Historical moment of a specialty. Saúde, Ética \& Justiça. 2010;15(2):69-74.

ABSTRACT: This article presents a brief history of Forensic Medicine in Brazil and emphasizes the current relevant moment the specialty is facing: fusion of two medical societies which disputed the right to issue specialty certification for forensic medical doctors working in the area. The main dispute points are discussed, including the change in denomination of the specialty with the addition of Perícia Médica to the original name (Medicina Lega).

KEY WORDS: Forensic medicine/history, Societies, medical/history; Specialization/history; Brazil.

\section{REFERÊNCIAS}

1. Muñoz DM. Medicina legal: uma especialidade médica. Saúde, Ética e Justiça. 1997;1(2):1-2.

2. Carvalho HV, Bruno AML, Segre M. Lições de medicina legal. São Paulo: Saraiva; 1965.
3. Calabuig JAG. Medicina legal e toxicologia. Barcelona: Masson; 1998.

4. Fávero F. Medicina legal. São Paulo: Martins; 1973.

5. Briand J, Chaudé E. Manuel complet de médicine 
Muñoz DR, Muñoz-Gianvecchio D, Gianvecchio VAP. Momento histórico de uma especialidade.

légale. Paris, Baullière et Fils; 1874.

6. Franchini A. Medicina legale in materia penale. Padova: Cedam; 1972.

7. Moriani G, Gerin C. Zacchia - Riv Med Legale Assicurazioni. 1937;1(15).

8. Roche L. Cotte L, David JJ, Saury A. La médicine légale sociale. Paris: Masson; 1966.

9. Basile AA, Novoa ECAD, Gonzáles OS. Medicina legal del trabajo y seguridad social. Buenos Aires: Abaco; 1983.

10. Alcântara HR. Perícia médica judicial. Rio de Janeiro: Guanabara Koogan; 2006.

Recebido em: 01/11/2010

Aprovado em: 25/11/2010 